\title{
Business Process Analysis and Improvement during Covid-19 Crisis: a Case of Frozen Shrimp Manufacturer
}

\author{
Sasita Hechaipoom and Pornthipa Ongkunaruk ${ }^{*}$ \\ Department of Agro-Industrial Technology, Faculty of Agro-Industry, Kasetsart University 50 \\ Ngamwongwan Rd., Lad Yao, Chatuchak, Bangkok 10900, Thailand
}

\begin{abstract}
Frozen shrimp is one of the major export products of Thailand. This research studied a frozen shrimp products supply chain, which is a large-sized manufacturer in central Thailand. Our objectives were to study the current supply chain of a frozen shrimp processor in Samut Sakhon province and propose suggestions to improve efficiency in each activity, especially to cope with the Covid-19 crisis. First, we analyzed its business process by using Integration Definition for Function Modeling (IDEF0) to investigate the stakeholders in the supply chain and the business process of the frozen shrimp manufacturer. After analysis, we identified problems and proposed how to improve efficiencies such as risk management, especially for shrimp and labor shortage. The supplier relationship should be established along with the contract, forecast price, and demand for shrimps to optimize the procurement. The labor should be trained for multi-skill and lean production should be applied to increase productivity. Finally, digitization should be fully transformed and set up the centralized information to reduce time, increase accuracy and share the data with partners. In summary, our guidelines for the frozen shrimp manufacturer could be applied to similar manufacturers to improve supply chain efficiency.
\end{abstract}

\section{Introduction}

Shrimp is one of the major export products of Thailand with mainly in a frozen form [1]. The main export markets for Thai shrimp products include the USA, Taiwan, South Korea, Malaysia, and Hongkong [2]. During the COVID-19, a new coronavirus disease that has rapidly spread over the world has had a disastrous influence on not only people's lives but on the economies of countries throughout the world. Thailand has been affected by the COVID-19 pandemic, which heavily impacts the fisheries industry, especially on the socioeconomic conditions of the stakeholders, such as shrimp farmers, collectors, manufacturers, central markets, and consumers, as well as the closure of food services along the supply chain that cause shrimp products decreased and exports began to slow down. Thailand's shrimp production in 2020 was 270,000 tonnes, a decrease of 7 percent from 290,000

\footnotetext{
${ }^{*}$ Corresponding author: pornthipa.o@ku.ac.th
} 
tonnes in 2019. The export value from the first 10 months in 2020 was only 123,297 tonnes, with values 35,872 million baht, compared to the same period of 2019 that exported 135,249 tonnes, with values 40,185 million baht, a decrease of 9 and 11 percent, respectively [2]. The main causes were shrimp diseases and weak demand during the pandemic. However, consumer awareness towards food safety also affects the demand for the high quality of frozen shrimp that need to handle under the appropriate cold chain and food hygiene to maintain the quality [3]. Therefore, in this research, we explored a case study of a frozen shrimp manufacturer located in Samut Sakhon, Thailand. We selected this company because it is the second-largest exporter from Thailand to the United States with an export value of 2,692.64 tonnes per year [4] and the top management team agreed to provide insight information for conducting this study. Since shrimp is one of the major export products of Thailand and the industry is affected by the Covid-19 situation. Hence, our objectives were to study the current supply chain of the frozen shrimp processor during the Covid-19 pandemic, identify the problems, and proposed suggestions to improve efficiency in each activity to assist the manufacturer to survive in this difficult situation.

\section{Methodology}

We conducted an in-depth interview to obtain qualitative data for analysis. An in-depth interview has been conducted with the factory manager and the financial manager of the frozen shrimp manufacturer who are responsible for gather required information to figure out the activities and problems of the frozen shrimp products supply chain. The interview questions were related to company background, their stakeholders in the supply chain, their roles, the activities, and problems in the value chain. Then, we analyze the business process based on integration definition for function modeling (IDEF0), which is a business process diagram, analysis, and improvement tool. It demonstrates the facts of the operational process that are linked from the first to the last process of the supply chain. Furthermore, it enables the understanding of the problems of different perspectives and levels of the model starting from level 0 which is the organization level that describes the relationship among stakeholders. Level 1 and so on are the internal process levels. The higher number of levels implies the detail of activities involved in the business model [5]. IDEF0 is a model of an organization's or system's decisions, actions, and activities. The activities are denoted as square boxes in the models, such as planning, sourcing, making, delivering, and returning. Each activity box has a code in the lower right corner that specifies the activity's rank, such as A1, A2, A3, A4, and A5. Each box contains four types of arrows that distinguish the input, output, control, and mechanism of activities in the supply chain. The arrow entering the box represents the input as the factor driving the activities, the arrow exiting the box represents the output as the result of doing the activity, the arrow above the box represents the control as the specification, capacity, time, regulation, standard or requirement of the activity, and the arrow below the box represents the mechanism or resources to pursue the activity such as staff, equipment, and machines. Furthermore, the solid lines represent the current activities (As-Is), while the dashed lines represent how to upgrade and enhance the efficiency of the frozen shrimp supply chain (To$\mathrm{Be})$.

The IDEF0 was also used in analyzing the business process in several industries, such as chicken-based pet food [6], a cordyceps beverage [7], canned pet food [8], a case study of alcohol sanitizer during COVID-19 [9], a chilled beef supply chain [10], a third-party logistics provider in Indonesian [11], a primary shrimp processor [12], a small-sized Thai chili paste [13], a raw milk collection center [14], a blue crab manufacturer [15], a case study of HORECAs [16], an organic rice company [17], etc. These case studies showed that the analysis of supply chain activities is important for improvement. 


\section{Results and Discussion}

\subsection{Background of the frozen shrimp manufacturer}

A case study company is a frozen food manufacturer established in 1980 located in Mahachai, Samut Sakhon province from a family-owned and operated company with experience in the seafood sector. At present, there are 850 full-time workers. The company is one of the pioneers for processing and exporting farm-raised shrimp. To keep ahead of ever-changing customer demand and rigid requirement regulations, the manufacturer must ensure that quality control is strictly in place to meet and exceed international standards including HACCP, GMP, ISO 9001 (Version 2015), BRC (Issue 7), ISO 22000, and BAP. There are three processing lines for the production of value-added products i.e., raw and par-fried shrimp, cooked shrimp and cooked tail-off shrimp, and frozen raw shrimp.

\subsection{Business process analysis of the frozen shrimp supply chain}

The business process analysis of the frozen shrimp supply chain was analyzed by IDEF0 level 0 or the organization level which indicated the relationship of stakeholders in the supply chain, as shown in Fig. 1. The stakeholders of the frozen shrimp supply chain and their roles were explained in Table 1.

The supply chain of this case study starts from white shrimp farmers asking for a certificate from the Department of Fisheries (DOF) first for cultivation. In shrimp production, the farmers follow good aquaculture practices and quality control. After shrimps grow to a suitable size according to the customer requirement, they will be harvested. The farmer will request a movement document from the DOF to move the shrimp to the destination. After harvesting, shrimp will be collected, cleaned, graded, and delivered to the factory by local brokers or collectors. Shrimp will be kept in a large-sized container with ice to maintain the best condition. Next, it will be delivered to the factory within the specified time.

Since shrimp quantity and price fluctuates, the company will buy shrimp from a nearby central market as well. After arrival, shrimp will be inspected for physical properties and weight. After passing the inspection, shrimp will be cleaned, peeled, cut, and processed. The processing was operated under the standards and regulations of the DOF. After that, the finished products will be delivered to the customer through shipping agents via ship.

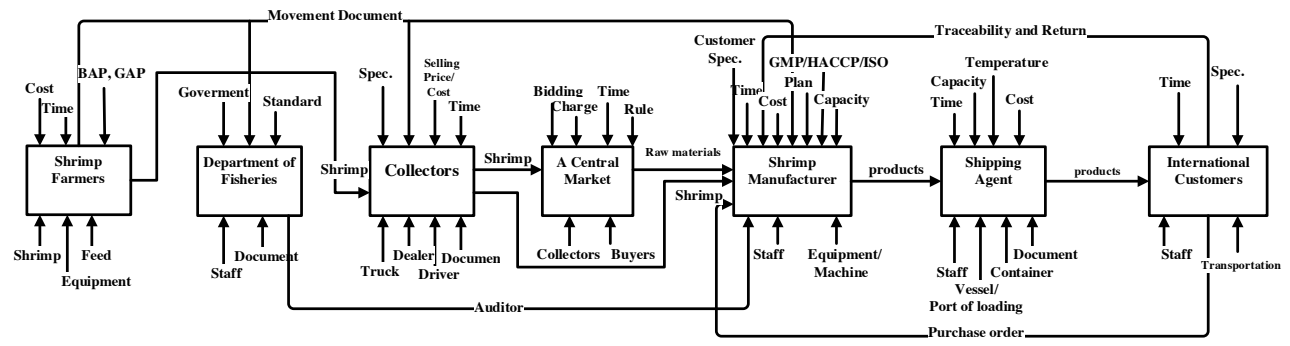

Fig. 1. The business process of the frozen shrimp manufacturer at IDEF0 level 0 
Table 1. The stakeholders of the frozen shrimp supply chain and their roles.

\begin{tabular}{|l|l|}
\hline Stakeholders & Description and Roles \\
\hline Shrimp farmers & $\begin{array}{l}\text { Most farmers are in the South and East of Thailand. Farmers know } \\
\text { shrimp cultivation. They are certified by the Department of Fisheries. } \\
\text { The cultivation area is following the GAP standard. After the shrimp } \\
\text { grows up to the size that customers require, the farmer will inform the } \\
\text { collectors. }\end{array}$ \\
\hline $\begin{array}{l}\text { The Department of } \\
\text { Fisheries (DOF) }\end{array}$ & $\begin{array}{l}\text { DOF is a government agency that controls related activities from farms } \\
\text { to manufacturers such as establishing the regulations, traceability } \\
\text { system and improving the efficiency of problems, control the } \\
\text { production to follow good practices such as GAP in farms and GMP } \\
\text { and HACCP in the manufacturers. }\end{array}$ \\
\hline Collectors & $\begin{array}{l}\text { The brokers or middlemen who grade and bargain the price of shrimp } \\
\text { from farmers, then gather shrimp and deliver to processing plants by } \\
\text { their trucks using ice to control the temperature of shrimps. }\end{array}$ \\
\hline Thale Thai market & $\begin{array}{l}\text { The largest seafood central market in Thailand is located in Samut } \\
\text { Sakhon. Shrimps from many sources are gathered together and sell to } \\
\text { customers by bidding. }\end{array}$ \\
\hline Shrimp manufacturer & $\begin{array}{l}\text { The manufacturer that added value to shrimps including raw and par- } \\
\text { fried, cooked shrimp and cooked tail-off shrimp, raw shrimp. In } \\
\text { addition, they exported their product to the USA (90\%), China, and } \\
\text { Japan. So, they have to follow the standard such as HACCP, GMP, } \\
\text { ISO 9001 (version 2015), IFS, BRC, ISO 22000, and BAP. }\end{array}$ \\
\hline Shipping agent & $\begin{array}{l}\text { The shipping agent will pick up finished products from the warehouse } \\
\text { and put them in the container to transport to the port and exported them } \\
\text { to the customer's country via sea freight. }\end{array}$ \\
\hline Domestic and International consumers \\
\hline Consumers
\end{tabular}

\subsection{Business process analysis of the frozen shrimp manufacturer}

The major activities of the frozen shrimp manufacturer include plan, source, make, delivery and return are as follows and can be visualized in Fig. 2.

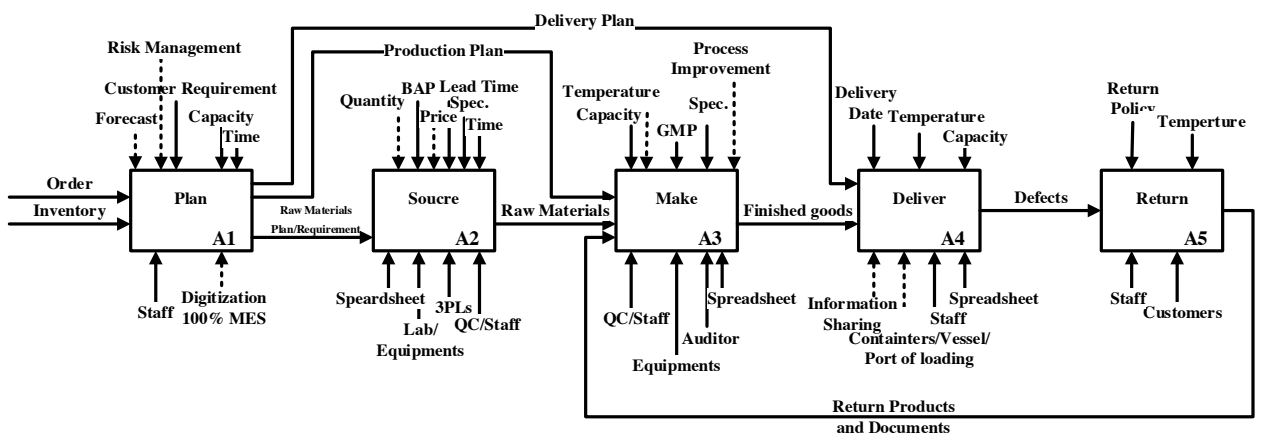

Fig. 2. The business process of the frozen shrimp manufacturer at IDEF0 level 1

For planning, the company receives the order from customers about 1-2 months in advance. The manufacturing execution system (MES) is used to plan for production and warehouse weekly. The shipment must be ready 7 days before delivery to customers. The company also sets a delivery plan to align with the number of workers and the procurement plan which plans to order the raw materials for production in time. Shrimp price and quantity always fluctuate causing a shortage of raw materials. Hence, the company forecasts which 
and how much raw materials will be shortage in the future. The shrimp are kept in cold storage to mitigate the risk of shortage. During Covid-19, every company faced raw materials shortage. Thus, the company established a plan to seek new farmers or suppliers and make contracts with them. The company negotiates with customers to adjust the production plan during the shortage of raw materials.

For sourcing, the company implements centralized procurement where the purchasing department manages all orders. Pacific white shrimp is the main raw material of the manufacturer. There are two main sources of shrimp: collectors and the Thale Thai market. Before acceptance of raw materials, the company needs to check the quality by the quality control (QC) staff. They will randomly check antibiotic residue and the volume of sulfites residue in raw shrimp. If it goes over the standard, the company will reject that lot. The physical quality of raw shrimp affects the price. Ice is used to control the quality of raw shrimp to be fresh. Collectors need to control the temperature by using a cold chain to deliver the raw material.

For production, the company produces based on Make to Order and the production is labor-intensive. There are many factors to control according to customer specification including size, temperature, and time which require highly skilled workers for the production and quality control.

For delivering, the company exports the finished products by the shipping agent. Implementation of cold chain management to control the temperature, use a data logger to monitor the temperature inside the container. If the vessel is full, the delivery will be delayed, and the company needs to postpone the delivery.

For returning, the company implements quality assurance and strict quality control to reduce unacceptable defects in products since the non-conforming cost is high and the return process is complicated. However, the company has a procedure to discover the solution with the customers if the return has occurred.

\subsection{Problem analysis and proposed strategies for an improvement}

Currently, the production plan was estimated based on international customers. Most of the production is Make-to-Order, but the COVID-19 pandemic caused the customers too afraid to orders too long in advance. Many markets were lockdowns, curfews, and other distance control measures to respond to the pandemic. During the pandemic, the demand forecast accuracy is very low since the manufacturer used historical data which did not include a pandemic. Then, we suggested that the staff collects the sales and demand data from the beginning of the pandemic and implement a combination of qualitative and quantitative forecasting method to increase the forecasting accuracy [18].

Next, the company should establish a centralized information system so that key staff can monitor the data, update, and exchange information with partners in real-time. This could reduce the transaction time, increase accuracy and efficiency in the supply chain. Some reports are not digitized and could not be integrated with the MES system. Hence, the company should implement $100 \%$ digital transformation and perform data analysis.

The pandemic has led to a slowdown of farming and processing activities, so raw materials were shortage while export prices were dropping because of fluctuating demand. We suggested that they should make contracts and long-term relationships with the partners so as they have a common benefit. In a par-fried product processing, the problems are temperature control. Hence, we suggested they set the critical control point (CCP) at every risk point. In addition, the company should implement process improvements such as line balancing and lean production. During the crisis, the manufacturer could not recruit new workers so, they substituted workers from other departments which resulted in higher defective products. However, this is a short-term problem and could be solved by 
implementing risk management in the planning process, training workers to be able to perform several tasks. In addition, the manufacturer implements seal and bubble measures suggested by the Ministry of Health to prevent the spread of the virus in the factory and accommodation for migrant workers. The seal strategy is applied to the factory which provides on-site accommodation for their workers, meaning they will not be allowed to leave the premises. The bubble strategy is applied to the factory which has no on-site accommodation provided for their workers and it is difficult to control the movement of workers from their dormitories to their workplaces. Hence, the manufacturer provides workers with accommodation inside a factory and at designated locations that could be fully controlled and monitored [19]. The problem in delivery is insufficient of the carrier, vessel, container, and limited operations and workers, we suggested that they should update and exchange information in advance with the shipping agent so that they can plan or prepare sufficient carrier/vessel and container.

The summary of recent problems and suggestions for improvement was explained in Table 2 .

Table 2. Summary of current problems and suggestions for the improvement

\begin{tabular}{|l|l|l|}
\hline Activities & \multicolumn{1}{|c|}{ Problems } & \multicolumn{1}{|c|}{ Improvement suggestions } \\
\hline Plan & $\begin{array}{l}\text {-Low demand forecast accuracy due to } \\
\text { demand disruption from Covid-19 } \\
\text {-Some reports are not digitized and } \\
\text { could not be integrated with the MES } \\
\text { system }\end{array}$ & $\begin{array}{l}\text {-Risk management } \\
\text {-Update and exchange information with } \\
\text { partners in real-time } \\
\text {-Use the efficient forecasting methods } \\
\text {-Establish a centralized information system } \\
\text {-Digital transformation and perform the data } \\
\text { analysis }\end{array}$ \\
\hline Source & $\begin{array}{l}\text {-Raw materials price and quantity } \\
\text { fluctuate } \\
\text {-The central market was closed due to } \\
\text { Covid-19 which resulted in raw } \\
\text { materials shortage }\end{array}$ & $\begin{array}{l}\text {-Implement mixed quantitative and qualitative } \\
\text { forecasting for fluctuated raw materials } \\
\text { price and quantity) [18,20] } \\
\text {-Establish contracts and long-term } \\
\text { relationships with partners } \\
\text {-Preliminary food processing }\end{array}$ \\
\hline Make & $\begin{array}{l}\text {-More quality problems occurred due } \\
\text { to substituted workers }\end{array}$ & $\begin{array}{l}\text {-Training the labor to be able to perform } \\
\text { several tasks and ready for substitution } \\
\text {-Seal and bubble measures }\end{array}$ \\
\cline { 2 - 3 } & -Lack of process control & $\begin{array}{l}\text {-Implement the process improvement such as } \\
\text { line balancing [21,22] and lean production } \\
\text {-Set the critical control point (CCP) at every } \\
\text { risk point }\end{array}$ \\
\hline Deliver & $\begin{array}{l}\text { Insufficient carrier, vessel, and } \\
\text { container which resulted in a delivery } \\
\text { delay }\end{array}$ & $\begin{array}{l}\text {-Update and exchange information in advance } \\
\text { with the shipping agent so that they can deal } \\
\text { with insufficient carriers/vessels and } \\
\text { containers }\end{array}$ \\
\hline
\end{tabular}




\section{Conclusion}

The frozen shrimp manufacturer's current supply chain activities at IDEF0 levels 0 and 1 are plan, source, make, deliver, and return processes. Following that, the manufacturer's current problems were identified, and proposed suggestions for improvement were provided. All stakeholders were affected by Covid-19. Hence, they should be resilient to this unexpected disruption. The manufacturer should perform risk management and plan for all types of risks in advance. The main problems of this case were shrimp and labor shortage. The manufacturer should establish the supplier relationship with the contract, forecast price, and demand for shrimps to optimize the procurement. In addition, the company should train the labor to multi-skill and implement lean production to increase productivity. Finally, the digital transformation process should be expedited so that they can reach the centralized information, reduce time, increase accuracy and share the data with partners. These guidelines are beneficial and applied to similar manufacture to upgrade their supply chain efficiency and survive in the disruptive era.

Acknowledgments. The researchers would like to thank the company to provide the information for this research.

\section{References}

1. P. Kaewnuratchadasorn, M. Smithrithee, A. Sato, and W. Wanchana, Fish People 18, 2 (2020)

2. P. Arunmas, Bangkokpost (2020)

3. D. Nguanphan, The Raw, Chilled, Frozen and Processed Shrimp (Excluding Shrimp Cans) (2021)

4. U. States and I. Trade, 1 (2021)

5. G. R. Waissi, M. Demir, J. E. Humble, and B. Lev, Oper. Res. Perspect. 2, 106 (2015)

6. J. Monchan and P. Ongkunaruk, in 2021 IEEE 8th Int. Conf. Ind. Eng. Appl. (ICIEA 2021) (2021), pp. 406-410

7. P. Poochinya and P. Ongkunaruk, IOP Conf. Ser. Mater. Sci. Eng. 773, (2020)

8. C. Sarachainantakul and P. Ongkunaruk, in 2021 IEEE 8th Int. Conf. Ind. Eng. Appl. (ICIEA 2021) (2021), pp. 426-431

9. W. Panitsettakorn and P. Ongkunaruk, in 2021 IEEE 8th Int. Conf. Ind. Eng. Appl. (ICIEA 2021) (2021), pp. 417-421

10. R. J. Neisyafitri and P. Ongkunaruk, IOP Conf. Ser. Mater. Sci. Eng. 773, (2020)

11. S. P. Pradita and P. Ongkunaruk, IOP Conf. Ser. Mater. Sci. Eng. 526, (2019)

12. W. Yupensuk and P. Ongkunaruk, KnE Life Sci. 4, 162 (2018)

13. J. Srilarp and P. Ongkunaruk, IOP Conf. Ser. Mater. Sci. Eng. 773, (2020)

14. P. Ongkunaruk, Agric. Agric. Sci. Procedia 3, 35 (2015)

15. P. K Kongsup, Ongkunaruk, Kasetsart J. Soc. Sci. Fourth Coming (n.d.)

16. P. Ongkunaruk and A. Kessuvan, in 2013 10th Int. Conf. Serv. Syst. Serv. Manag. Proc. ICSSSM 2013 (2013), pp. 831-836

17. Y. Prasertwattanakul and P. Ongkunaruk, Int. Food Res. J. 25, 481 (2018)

18. T. Khamphinit and P. Ongkunaruk, KnE Life Sci. 3, 1 (2016) 
19. M. Taylor, Thethaiger (2021)

20. S. P. Pradita, P. Ongkunaruk, and T. Leingpibul, Int. J. Technol. 11, 144 (2020)

21. M. Chueprasert and P. Ongkunaruk, Int. Food Res. J. 22, 2313 (2015)

22. P. Ongkunaruk and W. Wongsatit, Bus. Process Manag. J. 20, 678 (2014) 